\title{
Cryptococcal meningitis: Clinical, diagnostic and therapeutic overviews
}

\author{
P. Satishchandra, T. Mathew, G. Gadre, S. Nagarathna, A. Chandramukhi ${ }^{\star}$ A. Mahadevan**, \\ S. K. Shankar**
}

Department of Neurology, *Neuromicrobiology and **Neuropathology, National Institute of Mental Health and Neurosciences (NIMHANS) and St. Johns Medical College Hospital, Bangalore, India

\begin{abstract}
Cryptococcal meningitis has emerged as a leading cause of infectious morbidity and mortality in patients with AIDS. Among the human immunodeficiency virus (HIV)-seropositive subjects, cryptococcal meningitis is the second most common cause of opportunistic neuro-infection. Current trends are changing due to the marked improvement of quality and length of life produced by highly active antiretroviral therapy (HAART). The introduction of generic HAART in India has resulted in an increase in the number of individuals getting treatment for HIV infection, as the cost of highly active antiretroviral therapy (HAART) has decreased 20- fold. Cryptococcal meningitis occurs in non-HIV patients who are immunodeficient due to diabetes, cancer, solid organ transplants, chemotherapeutic drugs, hematological malignancies etc and rarely in healthy individuals with no obvious predisposing factors. Diagnosis of cryptococcal meningitis is fairly straightforward once the diagnosis is considered in the differential diagnosis of chronic meningitis. Treatment of a patient with cryptococcal infection is a challenge for both the physician and the patient, but rewarding, as many would recover with timely and adequate antifungal therapy.
\end{abstract}

Key words: Meningitis, Cryptococcal, HIV, immunodeficiency

Many microorganisms can cause chronic meningitis. Although tuberculous meningitis is the most common form, with the advent of the acquired Immunodeficiency Syndrome (AIDS) pandemic, more and more cases of fungal meningitis especially due to cryptococcal infection are seen in clinical practice. Cryptococcal meningitis has emerged as a leading cause of infectious morbidity and mortality in patients with AIDS. ${ }^{[1]}$ Among the human immunodeficiency virus (HIV)-seropositive subjects, cryptococcal meningitis is the second most common cause of opportunistic neuro-infection and usually occurs in advanced HIV disease ${ }^{[2]}$ Cryptococcal meningitis is one of the AIDS-defining illnesses. ${ }^{[3]}$

Current trends are changing due to the marked improvement of quality and length of life produced by highly active antiretroviral therapy (HAART). ${ }^{[4]}$ The introduction of generic HAART in India has resulted in an increase in the number of individuals getting treatment for HIV infection, as the cost of highly active antiretroviral therapy (HAART) has decreased 20fold. Kumaraswamy et al., ${ }^{[5]}$ reported a decrease in the incidence of tuberculosis and opportunistic infections to $<2$ cases per 100 person-years in south India, while death rates decreased from 25 to 5 deaths per 100 person-years between 1997 and 2003.

Cryptococcal meningitis occurs in non-HIV patients who are immunodeficient due to diabetes, cancer, solid organ transplants, chemotherapeutic drugs, hematological malignancies etc and rarely in healthy individuals with no obvious predisposing factors. Mirza et $a l .{ }^{[6]}$ conducted a population-based surveillance during 1992-2000 in two areas of USA and found 1491 cases of cryptococcal infection, $11 \%$ of the total cohort in non-HIV patients. Diagnosis of cryptococcal meningitis is fairly straightforward once the diagnosis is considered in the differential diagnosis of chronic meningitis. Treatment of a patient with cryptococcal infection is a challenge for both the physician and the patient, but rewarding, as many would recover with timely and adequate antifungal therapy.

\section{Etiological Agent}

Cryptococcal meningitis is the most common form of fungal meningitis and is caused by Cryptococcus neoformans. C. neoformans is an encapsulated heterobasidiomycetous fungus. Traditionally, C. neoformans is classified into two varieties and five serotypes (A, B, C, D, AD) based on its capsule structure.

C. neoformans var. neoformans includes strains with serotypes $\mathrm{A}, \mathrm{D}$ and $\mathrm{AD}$, while $\mathrm{C}$. neoformans var. gatti includes serotypes B and C. Recent analyses of the URA5 
gene and DNA fingerprinting patterns have shown that the serotypes A and D have significant genetic differences. Hence, C. neoformans var. neoformans serotype A was recognized as a new variety and named $C$. neoformans var. grubii. [7] Seroypes A and D and AD hybrids are globally responsible for $98 \%$ of all cryptococcal infections in patients with AIDS. Serotypes B and C predominantly affect immunocompetent individuals, but have also been recently reported in patients with AIDS. ${ }^{[8,9]}$ Jain et al., ${ }^{[10]}$ studied 57 clinical isolates of cryptococci from several regions of India 51 of which were $C$. neoformans var. grubii, one was $C$. neoformans var. neoformans and five were $C$. neoformans var. gattii. Weathered pigeon droppings commonly contain $C$. neoformans var. neoformans and litter around the trees of the species Eucalyptus camaldulensis and Eucalyptus terreticornis contains Cryptococcus neoformans var. gattii. Guqnani et al., ${ }^{[11]}$ isolated C. neoformans var. gatti $i$ and C. neoformans var. grubii from the flowers and bark of eucalyptus trees in India. C. neoformans var gatti has also been isolated from the decaying wood inside trunk hollows of Syzygium cumini trees (Java plum, Indian black berry) from northwestern India. ${ }^{[12]}$

\section{Predisposing Factors}

Cryptococcal infection is commonly encountered in immunocompromised patients with impaired cellmediated immunity. In those with HIV infection, cryptococcal infection occurs in the advanced stages of the disease when the CD $4+$ count is usually less than 50-200 cells/ $\mu \mathrm{L}$. With the availability of highly active anti-retroviral therapy, the incidence of cryptococcosis is declining in HIV-infected patients due to significant increases in CD4+ cell counts and immune reconstitution especially in developed countries. ${ }^{[6]}$ Infection can also occur in patients on long-term steroid therapy, diabetes, cancer, renal failure, immunologic diseases, immunosuppressive treatment, solid organ transplant patients, those suffering from lymphoma, sarcoidosis and in some patients with idiopathic CD4+ lymphocytopenia ${ }^{[6,13]}$ [Table 1].

\section{Pathogenesis}

Pathogenesis is determined by the status of the host's

Table 1: Predisposing factors for cryptococcal infection ${ }^{[6,13]}$

human immunodeficiency virus infection

Corticosteroid therapy

Diabetes

Cancer

Immunologic diseases

Renal failure/dialysis

Lung disease

Lymphoma

Solid organ transplant patients

Idiopathic CD4 lymphocytopenia defences, the virulence of the cryptococcal strain and the size of the inoculum. The susceptible host comes into contact with cryptococci from the environment. The fungus enters the human body through inhalation into the lungs. In the alveoli, the yeasts come into contact with alveolar macrophages, which elicit an inflammatory response. This pulmonary infection is often asymptomatic but the organism may disseminate to other organs depending on the immune status of the individual. The cerebrospinal fluid is an ideal site for infection as it lacks complements and immunoglobulins. An enzyme called phenoloxidase present in C. neoformans is responsible for melanin production. Melanin may act as a virulence factor by making the organism resistant to leukocyte attack, decreasing lymphocyte proliferation and tumor necrosis factor production. The brain is rich with substrates that can react with phenoloxidase, e.g., L-dopamine, which may explain the affinity of $\mathrm{C}$. neoformans for the central nervous system. ${ }^{[13,14]}$

\section{Clinical features [Table 2, Figure 1]}

Cryptococcal meningitis commonly presents as chronic or subacute meningitis, but rarely has a rapid course [Figure 2]. Patients often present with severe unbearable headache with or without fever that is often severe enough to interfere with day-to-day

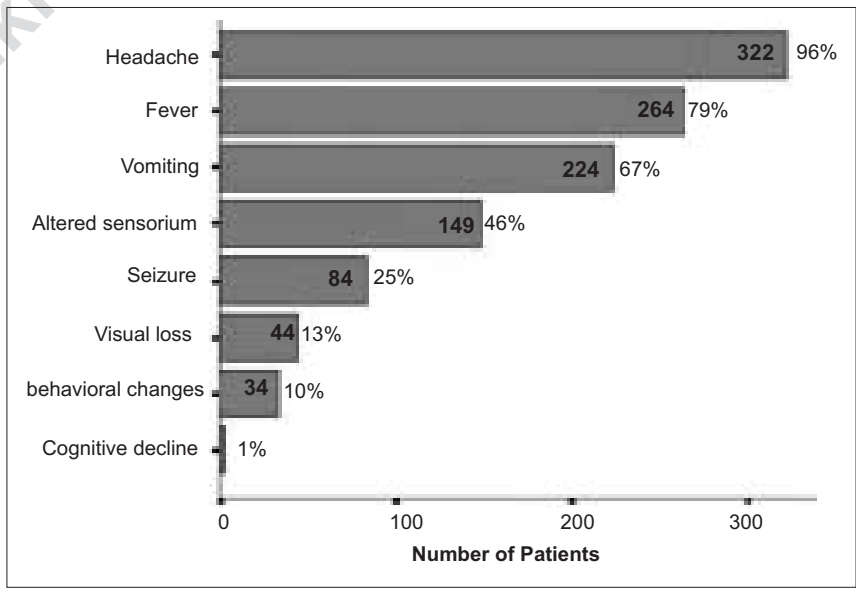

Figure 1: Clinical manifestations

Table 2: Cryptococcal meningitis in human immunodeficiency virus-seropositive and seronegative subjects

Duration of symptoms $>2$ weeks

Extracranial Involvement

Cryptococcomas

Mortality

Raised intracranial pressure

Raised positive India Ink

Cerebrospinal fluid antigen $>1: 1024$

Serum antigen

Cerebrospinal fluid culture

$\begin{array}{cc}\text { HIV- } & \text { HIV- } \\ \text { seropositive } & \text { seronegative } \\ + & ++ \\ ++++ & \pm \\ \pm & ++ \\ +++ & + \\ ++ & \pm \\ 80 \% & 50 \% \\ ++++ & + \\ ++++ & + \\ >90 \% & 75 \%\end{array}$




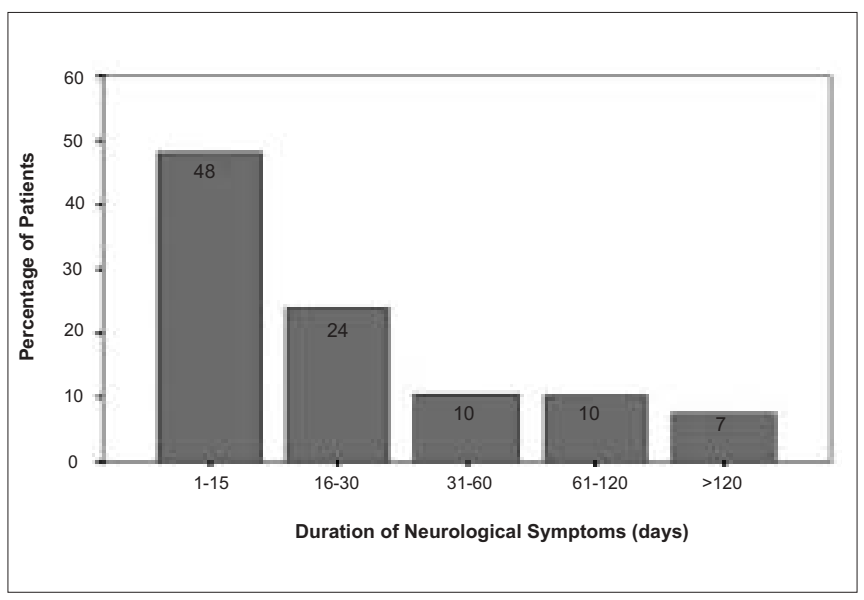

Figure 2: Duration of neurological symptoms

activities. Severe unbearable headache, either acute or subacute, without fever is a characteristic feature in patients with cryptococcal meningitis. Fever is seen in only $65 \%$ while headache is seen in $>75 \%$ of the patients. ${ }^{[15]}$ In a retrospective study conducted from 1989-2004 at NIMHANS, Bangalore, 335 HIVseropositive patients with cryptococcal meningitis were analyzed, duration of symptoms ranging from 1-120 days. Seventy two per cent of the patients presented within 30 days of symptom onset [Figure 2]. Ninety six per cent of these 335 patients had headache as their predominant clinical manifestation [Figure 1] while headache was associated with fever in $79 \%$ of the patients. Headache may be accompanied by vomiting and at times, there can be transient visual obscurations due to raised intracranial tension. In some instances, severe headache almost mimics headache associated with subarachnoid hemorrhage. The exact mechanism for such severe headache is not known, but it may due to meningeal involvement / raised intracranial tension / or sino-venous thrombosis. ${ }^{[16]}$ About $20 \%$ of the patients may develop altered sensorium, the presence of which denotes a poor prognosis. Altered sensorium was seen in $46 \%$ of the patients in the NIMHANS series. Around $13 \%$ of these patients had visual loss as a clinical manifestation in the current series. Seizures are seen in $<8 \%$ of cases, ${ }^{[17]}$ while seizures were observed in $25 \%$ of the patients with cryptococcal meningitis in our series [Figure 1]. Examination is usually unremarkable except for papilledema. Neck stiffness is seen in only $30 \%$ of the cases. One third of the patients can have disseminated infection with the involvement of the lungs, kidney or skin. A careful search for cutaneous cryptococcal lesions [Figure 3] can be rewarding in some cases of suspected cryptococcal meningitis. Focal deficits are uncommon but occasionally, patients can present with hemiparesis or hemisensory signs secondary to arteritis. ${ }^{[18]}$ Cranial neuropathies, especially of the lower cranial nerves, affecting one or more cranial nerves (II, VII, VIII, IX, X, XII) occur in isolated cases secondary to basal arachnoiditis or due to hydrocephalus. ${ }^{[19]}$ Cryptococcal meningitis in immunocompetent individuals is more commonly associated with papilloedema, hydrocephalus, focal deficits, seizures and cryptococcomas ${ }^{[20-22]}$ [Figure 4, Table 3].

Differential diagnosis to be considered in a case of suspected cryptococcal meningitis includes tuberculous meningitis and carcinomatous / lymphomatous meningitis. Cerebrospinal fluid (CSF) analysis will help in arriving at the correct etiological diagnosis. Cytospin analysis for malignant cells should be done in suspected cases of carcinomatous meningitis.

\section{Investigations}

Neuroimaging of the brain is carried out in all suspected cases of chronic meningitis before a lumbar puncture. A computed tomographic scan (CT) or magnetic resonance imaging (MRI) of the brain with contrast is done to rule out any focal space-occupying lesions like cryptococcomas and hydrocephalus [Figure 5]. CT brain or MRI brain is usually normal but may reveal diffuse atrophy of the brain. ${ }^{[23]}$ MRI brain may show punctate non-enhancing foci of CSF density correlating with the presence of cryptococcci in the Virchow-Robin spaces. Sometimes, MRI may even demonstrate pseudocyst [Figure 5]. Focal lesions consistent with cryptococcomas are seen only in a minority of patients [Table 3].

A lumbar puncture with manometry is the diagnostic procedure of choice and is carried out in all cases of suspected cryptococcal meningitis. CSF pressure may be elevated in some patients. The high levels of intracranial pressure at the initial tap do not always correlate with the clinical findings and it is recommended to measure opening pressures in all patients and not just in those with raised intracranial pressure. ${ }^{[24,25]}$

CSF analysis usually reveals lymphocytic pleocytosis with raised protein and low sugar levels. In the present series, $52 \%$ of the patients had $<20$ cells/cmm while only $20 \%$ had $>100$ cells/cmm. The diagnosis of cryptococcal meningitis can be established with India ink stain in $>50 \%$ of the cases of cryptococcal meningitis in HIV-negative cases and in $>90 \%$ of patients with AIDS [Figure 6]. ${ }^{[26-28]}$ The test will be considered positive when about $10^{3}-10^{4}$ colony-forming units (CFU)/ml are present in a CSF sample. AIDS patients have larger concentrations of yeast ranging between $10^{5}-10^{7} \mathrm{CFU} / \mathrm{ml}$. False-positive tests have been described when leukocytes, fat droplets, tissue cells or myelin globules are confused with yeast. Centrifuging the CSF to $500 \mathrm{rpm}$ for about 10 minutes and performing India ink stain on the pellet can improve the sensitivity of this test. ${ }^{[29]}$ The CSF sample should also be evaluated for cryptococcal antigen assay that is positive in almost 


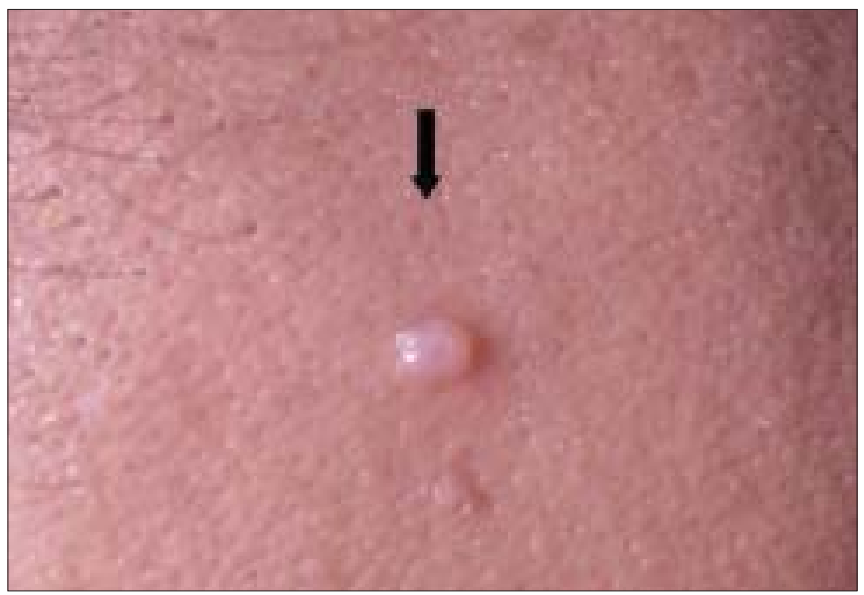

Figure 3: Cutaneous cryptococcal lesion (black arrow) from a case of cryptococcal meningitis (biopsy proved)

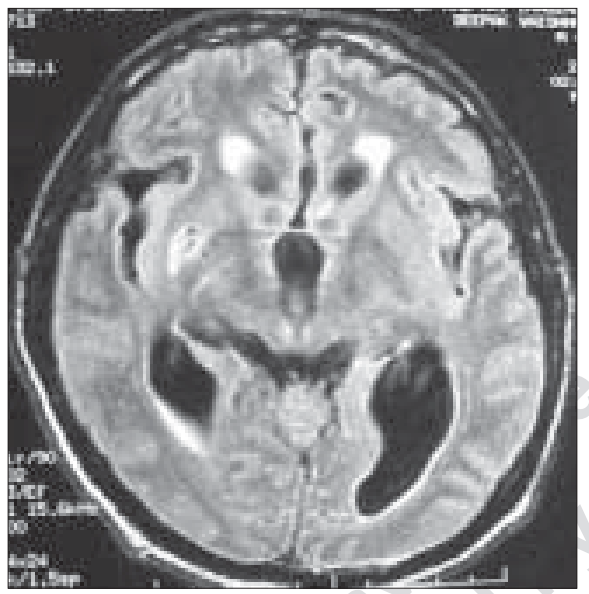

Figure 4: Communicative hydrocephalus in case of cryptococcal meningitis

Table 3: computerized tomography scan findings in patients with cryptococcal meningitis with and without HIV infection ${ }^{[41,42]}$

\section{HIV-seropositive}

Normal (50\%)

Diffuse cortical atrophy (34\%)

Hydrocephalus (9\%)

Focal masses $(11 \%)$

HIV - Human immunodeficiency virus

all cases except very early in the disease or in those with very high titers due to prozone effect and in certain patients with cryptococcomas. ${ }^{[17]}$ The methods used for antigen detection are latex agglutination test and enzyme immunoassay and are $>90 \%$ sensitive and specific. Cryptococcal antigen titers usually decrease with treatment but it can remain at low titers for long periods even after effective therapy. ${ }^{[30]}$ A positive fungal culture is the gold standard for diagnosis of cryptococcal infection and CSF samples shows fungal growth in almost all the cases. ${ }^{[31]}$ In the present NIMHANS series, fungal cultures grew C. neoformans in $100 \%$ of the cases. Fungal cultures also help to determine the species of the infecting organism and sensitivities to various

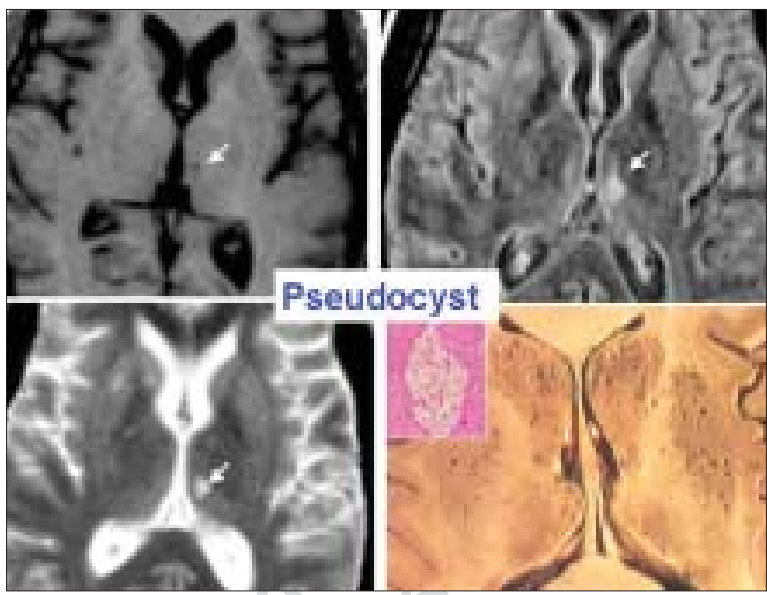

Figure 5: MRI demonstrating Pseudocyst formation

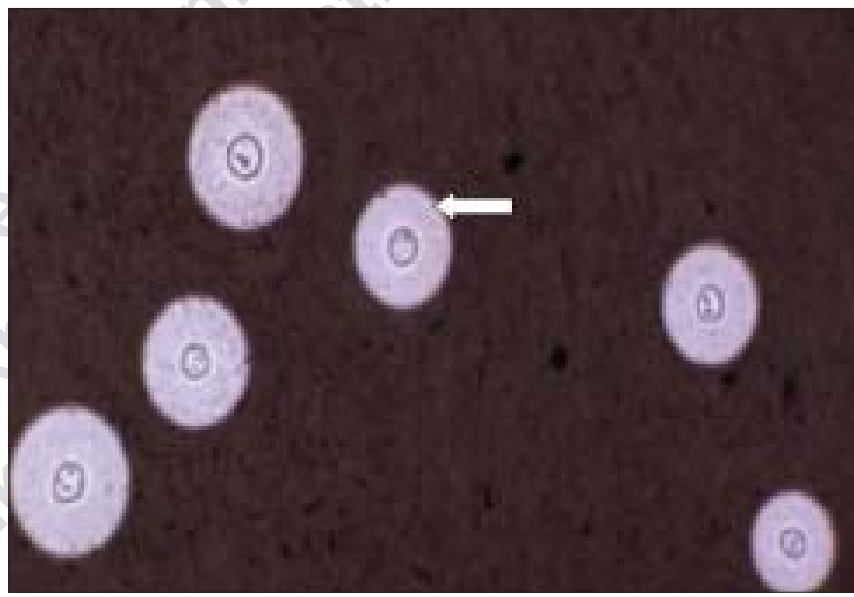

Figure 6: India ink stain showing capsulated cryptococci

antifungal agents. Drug susceptibility testing of the fungal isolates is not routinely done except in cases of recurrent disease.

\section{Treatment}

The nature and duration of treatment for cryptococcal infection is based on the immunity of the host and anatomic sites of involvement. For immunocompetent individuals with cryptococcal meningitis, the standard therapy consists of amphotericin B $0.7-1.0 \mathrm{mg} / \mathrm{kg} / \mathrm{day}$ along with 5-flucytosine $100 \mathrm{mg} / \mathrm{kg} /$ day for 6-10 weeks. An alternative to this regimen is amphotericin B 0.7$1.0 \mathrm{mg} / \mathrm{kg} /$ day plus 5 -flucytosine $100 \mathrm{mg} / \mathrm{kg} /$ day for two weeks, followed by fluconazole $400 \mathrm{mg} /$ day for a minimum of ten weeks. Fluconazole "consolidation" therapy may be continued for as long as 6-12 months, depending on the clinical status of the patient. For patients with HIV infection and cryptococcal meningitis, induction therapy with amphotericin B 0.7-1.0 mg/ $\mathrm{kg} /$ day plus 5-flucytosine $100 \mathrm{mg} / \mathrm{kg} /$ day is given for two weeks, followed by fluconazole $400 \mathrm{mg} /$ day for a 
minimum of ten weeks. After ten weeks of therapy, the fluconazole dosage may be reduced to $200 \mathrm{mg} /$ day, depending on the clinical status of the patient. ${ }^{[32]}$ Fluconazole should be continued for life or at least up to the time the CD4+ count reaches $350 / \mathrm{cmm}$.

Our practice is to start intravenous amphotericin B immediately once the India ink stain or cryptococcal antigen assay is positive for cryptococcal infection. Oral fluconazole is also begun along with amphotericin B to reduce the total dose of the latter and thereby decrease the duration of hospitalization. Flucytosine is not routinely used in India due to lack of availability and the high cost. Monitoring of serum creatinine and potassium levels should be done frequently (once a week) when amphotericin B is administered. Appropriate dose correction should be made in case of renal involvement and when hypokalemia is encountered. Either conventional amphotericin B or liposomal preparations can be used. Although liposomal preparations have many advantages such as the administration of higher doses over a short span of time with less adverse effects, the cost is prohibitive. ${ }^{[33]}$ Itraconazole albeit less effective, may be a suitable alternative for patients intolerant to fluconazole. ${ }^{[34]}$

If there is no clinical resolution after acute treatment (10-12 weeks) for cyrptococcal culture, a repeat lumbar puncture should be done,. If cryptococcus is still grown from CSF, then acute treatment should be continued considering possible dose changes to the existing therapy or addition of other antifungal agents. Repeat susceptibility testing to antifungal agents may be helpful in selecting the most effective drugs.

Elevated intracranial pressure occurs in up to $75 \%$ of the patients with cryptococcal meningitis and is an important contributor to mortality and morbidity. Patients with raised intracranial tension should be treated aggressively. The principal intervention for reducing elevated intracranial pressure is percutaneous lumbar drainage. In patients with normal baseline opening pressure $\left(<200 \mathrm{~mm} \mathrm{H}_{2} \mathrm{O}\right)$, a repeat lumbar puncture should be performed two weeks after the initiation of therapy to exclude elevated pressure and to evaluate culture status. In patients with elevated baseline opening pressure, lumbar drainage should be done to reduce pressure by $50 \%$. Daily lumbar punctures are carried out to maintain CSF opening pressure in the normal range. Once CSF pressure is normal for several days, lumbar puncture can be stopped. When frequent lumbar punctures are required or fail to control symptoms of elevated intracranial pressure, a lumbar drain may be considered. Ventriculoperitoneal shunting may be considered when the above measures fail to control raised intracranial pressure and also in patients with hydrocephalus. ${ }^{[32]}$

Antiretroviral therapy is usually started when the clinical condition of the patient is relatively stable especially in those with very low CD4+ $(<100$ cells $/$ $\mathrm{cmm}$ ) counts. The possibility of immune reactivation inflammatory syndrome (IRIS) should be considered when patients develop new neurological deficits with an improving CD4+ count. Patients with cryptococcal IRIS can present as meningitis, intracranial mass lesions, pulmonary cavitation or lymphadenitis. ${ }^{[35]}$ It usually occurs after a few weeks or a few months and is treated with steroids or nonsteroidal, antiinflammatory drugs. ${ }^{[36]}$ Bilateral blindness has also been reported after starting antiretroviral therapy in a patient with cryptococcal meningitis. ${ }^{[37]}$

\section{Prognosis}

The majority of the patients with cryptococcal meningitis improve with adequate therapy. Mortality is seen in about $10 \%$ of the cases while morbidity is unusual. Mortality is more common in HIV-positive individuals. Sudden deaths are encountered occasionally, the cause for this is not exactly known. The poor prognostic factors are depressed levels of consciousness, signs of raised intracranial pressure, depressed CSF cell counts and glucose levels and CSF cryptococcal antigen titer $>1024^{[38]}$ [Table 4]. The most important of all the poor prognostic factors is the CSF opening pressure with values $\geq 250 \mathrm{~mm} \mathrm{H}_{2} \mathrm{O}$ being particularly significant. ${ }^{[39]}$ A significant proportion of patients can develop various neurological sequelae, which include visual loss, decreased mental capacity, hearing loss, permanent cranial nerve palsies and hydrocephalus [Table 5]. Visual impairment may result from either direct invasion of the optic nerve by cryptococci or from the increased intracranial pressure. ${ }^{[40]}$

In the present series of cryptococcal meningitis among immunodeficient individuals, autopsy was done in 57 cases, which confirmed the diagnosis of cryptococcal

\section{Table 4: Poor prognostic factors in patients with cryptococcal infection $^{[17,38]}$}

Depressed level of consciousness

Papilloedema

$6^{\text {th }}$ nerve palsy

Hydrocephalus on brain imaging

Elevated cerebrospinal fluid opening pressure $\left(\geq 250 \mathrm{~mm} \mathrm{H}_{2} \mathrm{O}\right)$

Depressed cerebrospinal fluid glucose

Initial India ink positivity

CSF antigen titer $>1024$

Extra-central nervous system culture positive sites (e.g, blood cultures, urine culture etc.)

Lymphoreticular malignancies

Corticosteroid therapy

Table 5: Neurological sequelae in cryptococcal meningitis ${ }^{[38}$

Cognitive impairment (31\%)

Visual loss (8\%)

Motor impairment (5\%)

Cranial palsies (3\%) 


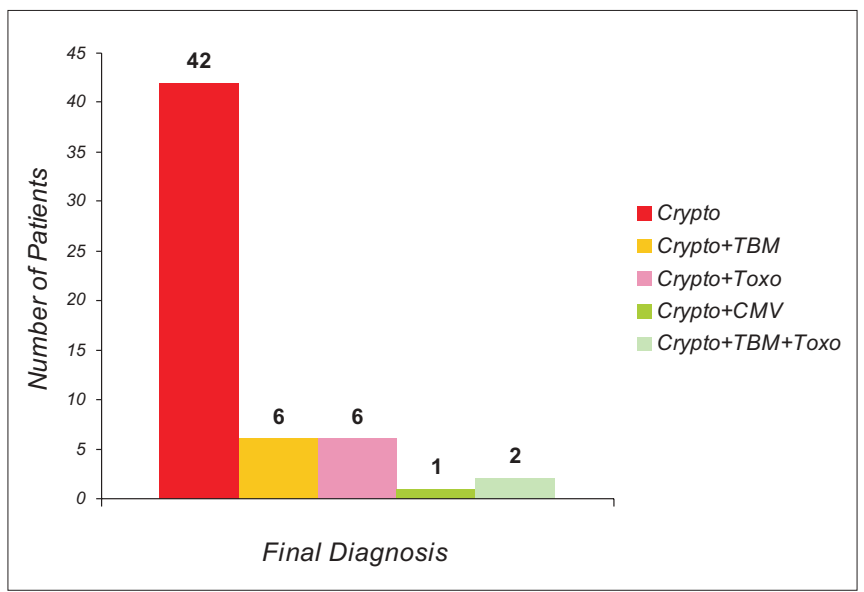

Figure 7: Cryptococcal meningitis In HIVIAIDS autopsy $(n=57)$

infection in 42 cases and mixed infections in the remaining 15 cases (Unpublished data) [Figure 7].

\section{Conclusion}

Cryptococcal meningitis is the most common, opportunistic, fungal infection of the nervous system in immunocompromised individuals. A high index of suspicion is needed for early diagnosis and it is a good clinical practice to use India ink stain and the cryptococcal antigen assay in all cases of meningitis. Early diagnosis and adequate treatment may save the lives of these unfortunate patients. With the advent of antiretroviral therapy, the incidence of opportunistic infections is on a decline in developed countries. In developing countries also, as in India, the incidence of cryptococcal infections may decline in the future with increasing access to antiretroviral therapy.

\section{References}

1. Mitchell TG, Perfect JR. Cryptococeosis in the era of AIDS-100 years after the discovery of Cryptococcus neoformans. Clin Microbiol Rev 1995;8:515-48.

2. Currie BP, Casadevall A. Estimation of the prevalence of cryptococcal infection among patients infected with the human immunodeficiency virus in New York City. Clin Infect Dis 1994:19:1029-33.

3. Clark RA, Greer D, Atkinson W, Valainis GT, Hyslop N. Spectrum of Cryptococcus neoformans infection in 68 patients infected with human immunodeficiency virus. Rev Infect Dis 1990;12:768-77.

4. Palella FJ, Delaney KM, Moorman AC, Loveless MO, Fuhrer J, Satten GA, et al. Holmberg SD and HIV Outpatient Study Investigators. Declining mortality and morbidity among patients with advanced human immunodeficiency virus infection. N Engl J Med 1998;338:853-60.

5. Kumarasamy N, Solomon S, Chaguturu SK, Cecelia AJ, Vallabhaneni S, Flanigan TP, et al. The changing natural history of HIV disease: Before and after the introduction of generic antiretroviral therapy in southern India. Clin Infect Dis 2005;41:1525-8.

6. Mirza SA, Phelan M, Rimland D, Graviss E, Hamill R, Brandt ME, et al. The changing epidemiology of cryptococcosis: An update from population-based active surveillance in 2 large metropolitan areas, 1992-2000. Clin Infect Dis 2003;36:789-94.

7. Franzot SP, Salkin IF, Casadevall A. Cryptococcus neoformans var grubii: Separate varietal status for Cryptococcus neoformans serotype A isolates.
J Clin Microbiol 1999;37:838-40.

8. Litvintseva AP, Thakur R, Reller LB, Mitchell TG. Prevalence of clinical isolates of Cryptoccus gattii serotype $\mathrm{C}$ among patients with AIDS in Sub-Saharan Africa. J Infect Dis 2005;192:888-92.

9. Bennet JE. Cyrptococcosis. In: Kasper DL, Braunwald E, Fauci AS, Hauser SL, Longo DL, Jameson JL, editors. Harrison's Principles of Internal Medicine. $16^{\text {th }}$ ed. The McGraw-Hill Co: USA; 2005. p. 11835 .

10. Jain N, Wickes BL, Keller SM, Fu J, Casadevall A, Jain P, et al. Molecular epidemiology of clinical cryptococeus strains from India. J Clin Microbiol 2005;43:5733-42.

11. Gugnani HC, Mitchell TG, Litvintseva AP, Lengeler KB, Heitman J, Kumar A, et al. Isolation of Cryptococcus gattii and Cryptococcus neoformans var. grubii from the flowers and bark of Eucalyptus trees in India. Med Mycol 2005;43:565-9.

12. Randhawa HS, Kowshik T, Preeti Sinha K, Chowdhary A, Khan ZU, Yan Z, et al. Distribution of Cryptococcus gattii and Cryptococcus neoformans in decayed trunk wood of Syzygi um cumini trees in north-western India. Med Mycol 2006;44:623-30.

13. Forbes BA, Sahm DF, Weisfeld AS. Laboratory methods in basic mycology. In: Bailey and Scott's Diagnostic Microbiology. $11^{\text {th }}$ ed. Mosby, Inc: USA; 2002.p. 724-5.

14. Casadevall A, Rosas AL, Nosanchuk JD. Melanin and virulence in Cryptococcus neoformans. Curr Opin Microbiol 2000;3:354-8.

15. Chuck SL, Sande MA. Infections with Cryptococcus neoformans in the acquired immunodeficiency syndrome. N Engl J Med 1989;321:7949.

16. Satishchandra P, Nalini A, Gourie-Devi M, Khanna N, Santosh V, Ravi $\mathrm{V}$, et al. Profile of neurological disorders associated with HIV/AIDS from South India (1989 - 1996). Indian J Med Res 2000;111:14-23.

17. Brew BJ. Cryptococcal meningitis. In: HIV neurology. Oxford University Press: New York; 2001. p. 91-6.

18. Leite AG, Vidal JE, Bonasser Filho F, Nogueira RS, Oliveira AC. Cerebral infarction related to cryptococcal meningitis in an HIV-infected patient: case report and literature review. Braz J Infect Dis 2004;8:1759.

19. Mohan S, Ahmed SI, Alao OA, Schliep TC. A case of AIDS associated cryptococcal meningitis with multiple cranial nerve neuropathies. Clin Neurol Neurosurg 2006;108:610-3.

20. Kiertiburanakul S, Wirojtananugoon S, Pracharktam R, Sungkanuparph S. Cryptococeosis in human immunodeficiency virus-negative patients. Int J Infect Dis 2006;10:72-8.

21. Helbok R, Pongpakdee S, Yenjun S, Dent W, Beer R, Lackner P, et al. Chronic meningitis in Thailand: Clinical characteristies, laboratory data and outcome in patients with specific reference to tuberculosis and cryptococeosis. Neuroepidemiology 2006;26:37-44.

22. Chen S, Sorrell T, Nimmo G, Speed B, Currie B, Ellis D, et al. Epidemiology and host- and variety-dependent characteristics of infection due to Cryptococcus neoformans in Australia and New Zealand. Clin Infect Dis 2000;31:499-508.

23. Santosh V, Yasha TC, Panda KM. Pathology of AIDS: Study from a neuropsychiatric center from south India. Ann Indian Acad Neurol 1998;1:71-82.

24. Denning DW, Armstrong RW, Lewis BH, Stevens DA. Elevated cerebrospinal fluid pressures in patients with cryptococcal meningitis and acquired immunodeficiency syndrome. Am J Med 1991;91:26772 .

25. Graybill JR, Sobel J. The role of lumbar puncture in the management of elevated intracranial pressure in patients with AIDS-associated cryptococeal meningitis. Clin Infect Dis 2000;31:1310-1.

26. Chuck L, Sande MA. Infections with Cryptococcus neoformans in the acquired immunodeficiency syndrome. N Engl J Med 1989;321:7949.

27. Khanna N, Chandramukhi A, Desai A, Ravi V. Cryptococeal infection of the central nervous system and analysis of predisposing factors, laboratory findings and outcome inpatients from South India with special reference to HIV infection. J Med Microbiol 1996;45:376-9.

28. Pappas PG, Perfect JR, Cloud GA, Larsen RA, Pankey GA, Lancaster DJ, et al. Cryptococeosis in human immunodeficiency virus-negative patients in the era of effective azole therapy. Clin Infect Dis 2001;33:690-9. 
29. Casadevall A, Perfect JR. Cryptococcus neoformans. ASM Press: Washington DC; 1998.

30. Lu H, Zhou Y, Yin Y, Pan X. Cryptococcal antigen test revisited: significance for cryptococcal meningitis therapy monitoring in a tertiary Chinese hospital. J Clin Microbiol 2005;43:2989-90.

31. Khanna N, Chandramuki A, Desai A, Ravi V, Santhosh V, Shankar SK, et al. Cryptococeosis in the immunocompromized host with special reference to AIDS. Indian J Chest Dis Allied Sci 2000;42:311-5.

32. Saag MS, Graybill RJ, Larsen RA, Pappas PG, Perfect JR, Powderly WG, et al. Practice guidelines for the management of Cryptococcal disease. Clin Infect Dis 2000;30:710-8.

33. Chen SC; Australasian Society for Infectious Diseases (ASID) Mycoses Iterest Group. Cryptococcosis in Australasia and the treatment of cryptococeal and other fungal infections with liposomal amphotericin B. J Antimicrob Chemother 2002;49:57-61.

34. van der Horst CM, Saag MS, Cloud GA, Hamill RJ, Graybill JR, Sobel JD, et al. Treatment of cryptococcal meningitis associated with the acquired immunodeficiency syndrome. N Engl J Med 1997;337:15-21.

35. Jenny-Avital ER, Abadi M. Immune reconstitution cryptococcosis after initiation of suceessful highly active antiretroviral therapy. Clin Infect Dis 2002;35:e128-33.

36. Skiest DJ, Hester LJ, Hardy RD. Cryptococcal immune reconstitution inflammatory syndrome: Report of four cases in three patients and review of the literature. J Infect 2005;51:e289-97.

37. De Schacht C, Smets RM, Callens S, Colebunders R. Bilateral blindness after starting highly active antiretroviral treatment in a patient with HIV infection and cryptococcal meningitis. Acta Clin Belg 2005;60:10-2.

38. Diamond RD, Bennett JE. Prognostic factors in cryptococcal meningitis: A study in 111 cases. Ann Intern Med 1974;80:176-81.

39. Graybill JR, Sobel J, Saag M, van Der Horst C, Powderly W, Cloud $\mathrm{G}$, et al. Diagnosis and management of increased intracranial pressure in patients with AIDS and cryptococeal meningitis. Clin Infect Dis 2000;30:47-54.

40. Rex JH, Larsen RA, Dismukes WE, Cloud GA, Bennett JE. Catastrophic visual loss due to Cryptococcus neoformans meningitis. Medicine 1993;72:207-24

41. Popovich MJ, Arthur RH, Helmer E. CT of intracranial cryptococeosis. AJR Am J Roentgenol 1990;154:603-6.

42. Cornell SH, Jacoby CG. The varied computed tomographic appearance of intracranial cryptococcosis. Radiology 1982;143:703-7.

Accepted on 14-08-2007

Source of Support: Nil, Conflict of Interest: None declared. 